\title{
Preparation, Characterization, Viscosity and Thermal Analysis of a Schiff-Based Resin derived from 2-Methoxy-1-Napthaldehyde
}

\author{
Moina Akhtar Mughal ${ }^{1}$, Akhtar H. Mughal ${ }^{2}$, Zeenat M. Ali ${ }^{3}$, \\ Ghulam Zuhra Memon ${ }^{1}$, Mohammad Yar Khuhawar ${ }^{4}$, Hussain Saleem ${ }^{5 *}$ \\ ${ }^{1}$ Dr. Mumtaz Ali Kazi Institute of Chemistry, University of Sindh, Jamshoro, Pakistan \\ ${ }^{2}$ Institute of Physics, University of Sindh, Jamshoro, Pakistan \\ ${ }^{3}$ Mehran University of Engineering \& Technology, Jamshoro, Sindh, Pakistan \\ ${ }^{4}$ Institute of Advanced Research Studies in Chemical Sciences, University of Sindh, Jamshoro, Pakistan \\ ${ }^{5}$ Department of Computer Science, University of Karachi, Karachi, Pakistan
}

\begin{abstract}
A New Schiff based resin Poly-methylene bis (2-methyoxy-1-napthaldehyde) 1, 2-propylenediimine (PMBMNPn) was synthesized by reacting with Formaldehyde (HCHO). The synthesized resin was categorized through elemental micro-analysis and Fourier transformation. The infrared, ultraviolet and visible spectroscopic analysis TGA/DTA and Viscometric studies were also carried out. The results of Carbon-Hydrogen-Nitrogen (CHN) Analysis were in good agreement with the considered values and reinforced the formation of the prepared resin. The resin indicated more strong absorption around 16 to $35 \mathrm{~cm}^{-1}$ of ${ }^{v} \mathrm{C}=N$ stretching vibration than the Schiff base, confirming the structure of synthesized resin. A shift of absorption maxima towards longer wavelength within 10 to $34 \mathrm{~nm}$ perceived in the initial 3 bands of compound PMBMNPn in comparison with BMNPn. A significant elevation in $\eta$ for resin was seen as compared to Schiff base.
\end{abstract}

Keywords: - Characterization, Resin, Synthesis, Thermo-gravimetery, Viscosity.

\section{INTRODUCTION}

The Schiff based resins establish significant type of ligands which have been widely considered in coordination chemistry because of its electronic and catalytic possessions [3]. The focused resins have been utilized for pre-concentration and split-up of trace elements from ocean. Their analytical usage in combination with AAS (Atomic Absorption Spectroscopy) has well been recognized [14] and these ligands are reflected by possessing responsive functional groups of Oxygen, Nitrogen, and Sulphur in backbone of the polymer, proficient of organizing to dissimilar metal ions [12]. The structure of polymer permits favored discrimination to some metal ions and thus there is a considerable alteration in the constancy of complexes [13]. Resins of Ureaformaldehyde possess profitable position especially as glues for wooden goods and are easy for construction at cheap prices. Carbon thirteen nuclear magnetic resonance was used to study $\left(\mathrm{F} / \mathrm{U}_{1}\right)$ mole ratio for preparing compound [9]. Thermo setting polyimide Schiff base resins find applications in electronics for making conducting or insulating thermo stable glues in the field of structural materials to prepare composite matrices [11]. Cyclohexene-formaldehyde resins can expand adhesion, rigidity and luster of covering films [16]. These can also be used as adhesives in rough coats [10]. Water proofing arrangement centered on acetone formaldehyde resin is established to elevate the efficacy of repair works to save wells from flow of water. A Salicylic acid-formaldehyde copolymer, having Orcinol (SFO), a chelating resin was found constant in acidic conditions, and was considered via Fourier transform, infrared analysis, elemental analysis, scanning electron microscopy, XRD (X-Ray Diffraction) and optical photographs [2]. Different Schiff base polymers have been produced and categorized spectroscopically and are described as arrangement of ligands [5]. The study under investigation reports the preparation, characterization, viscosity and thermal analysis of a newly formed resin, by a general method [4],[6]. These are (1) Polymethylene bis (2-methoxy-1-napthaldehyde) 1, (2) 2-diiminopropane (PMBMNPn). 


\section{MEASUREMENTS}

The CHN (Carbon-Hydrogen-Nitrogen) Analysis was performed at Elemental Microanalysis Ltd. Devon, England, H.E.J. Research Institute of Chemistry, University of Karachi, Pakistan and NCEAC Sindh University, Jamshoro. The spectra were recorded on Nicolet Avatar 330 FT-IR (Thermo Nicolet Electron Corporation, USA) with ATR (Attenuated Total Reflectance) accessory (Smart Partner) between 4000-600 $\mathrm{cm}^{-1}$. The Ultraviolet/Vis spectrums of the prepared compounds were recorded in DMF on $\lambda 35$ double beam Spectrophotometer. Quartz glass cells of one centimeter path length were used. The graphs were documented within $190 \mathrm{~nm}$ to $700 \mathrm{~nm}$. The Thermo Analytical Graphs (TAG) were attained by using Pyris Diamond TGA (Thermal Gravimetric Analysis)/DTA (Differential Thermal Analysis) i.e. TA (Thermal Analyzer) from $24^{\circ} \mathrm{C}$ upto $600^{\circ} \mathrm{C}$ with a nitrogen flow rate of $5 \mathrm{~mL} / \mathrm{min}$, on a heating rate of $25^{\circ} \mathrm{C} / \mathrm{min}$ in an inert atmosphere. The viscosity of the prepared compound was calculated by means of the standardized Ostwald's Viscometer, with Gallen Kamp thermally controlled bath containing water. The flow time of solvent Dimethyl formamide (DMF) was recorded within 283 to $323^{\circ} \mathrm{K}$ with an intermission of $10^{\circ} \mathrm{K}$ (Kelvin).

\subsection{Materials and Methods}

\section{EXPERIMENTAL WORK}

2-methoxy-1-napthaldehyde, (Fluka, Switzerland) $\mathrm{CH}_{2} \mathrm{NH}_{2} \mathrm{CHNH}_{2} \mathrm{CH}_{3}$ (E. Merck, Germany), (DMF). $\mathrm{C}_{2} \mathrm{H}_{5} \mathrm{OC}_{2} \mathrm{H}_{5}$ and $\mathrm{CH}_{3} \mathrm{COOH}$ (Germany), Etoh, normal-hexane (E. Merck, Germany).

\subsection{Preparation of (BMNPn)}

One gram of 2-methoxy-1-napthaldehyde was added to $0.198 \mathrm{~mL}$ of $\mathrm{CH}_{2} \mathrm{NH}_{2} \mathrm{CHNH}_{2} \mathrm{CH}_{3}$ dissoluted in $15 \mathrm{~mL}$ of ethanol and then was refluxed for 30 minutes. The resultant oily mixture was melted in $\mathrm{C}_{2} \mathrm{H}_{5} \mathrm{OC}_{2} \mathrm{H}_{5}$ and added equivalent amount of normal-hexane. The compound crystallized and was recrystallized from ethyl alcohol. The resultant precipitates were oven dried for 4 hours at $80^{\circ} \mathrm{C}$. The compound melted at $100^{\circ} \mathrm{C}$. Figure-1 shows the chemical scheme for preparation of Schiff base (BMNPn).<smiles>COc1ccc2ccccc2c1CNCc1cccc2ccccc12</smiles>

Fig.-1: Chemical Scheme for Preparation of Schiff base (BMNPn)

\subsection{Poly Condensation of Schiff base with Formaldehyde to form (PMBMNPn)}

One gram of BMNPn was added in $25 \mathrm{~mL}$ of distilled $\mathrm{H}_{2} \mathrm{O}$, agitated the combination for 10 to 15 minutes. 15 drops of 2 molar sodium hydroxide was added thereafter. The mixture was heated upto $60^{\circ} \mathrm{C}$ for 5 minutes and pure solution was added $37 \% \mathrm{HCHO}$ with it with 1:3 molar ratio. The product was boiled in bath containing oil at 120 to $130^{\circ} \mathrm{C}$ for 2 hours. The unsolvable resin was filtered, washed with $\mathrm{H}_{2} \mathrm{O}$ and $\mathrm{C}_{2} \mathrm{H}_{5} \mathrm{OC}_{2} \mathrm{H}_{5}$. The precipitates were than oven dried for 7 to 8 hours at 70 to $80^{\circ} \mathrm{C}$. The recovered compound was recrystallized from Etoh. The compound melted at $121^{\circ} \mathrm{C}$. Figure- 2 shows the chemical scheme for preparation of Resin (PMBMNPn).

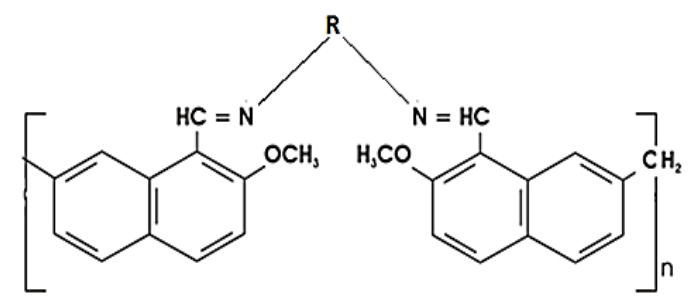

Fig.-2: Chemical Scheme for Preparation of Resin (PMBMNPn) 


\section{RESULTS AND DISCUSSION}

The Schiff base BMNPn, and resin PMBMNPn were prepared by a general method, and achieved in accessible yields. The results of CHN Analysis related closely to the calculated values as shown in Table-1.

Table-1: CHN Analysis of Schiff base BMNPn, and resin PMBMNPn

\begin{tabular}{l|c|c|ccc}
\hline \multirow{2}{*}{ Compound } & \multirow{2}{*}{ Chemical Formula } & \multirow{2}{*}{ Melting Point } & \multicolumn{3}{c}{ Calculated \% (Found \%) } \\
\cline { 4 - 6 } & & & $\mathbf{C}$ & $\mathbf{H}$ & $\mathbf{N}$ \\
\hline BMNPn (Schiff base) & $\mathrm{C}_{27} \mathrm{H}_{26} \mathrm{~N}_{2} \mathrm{O}_{2}$ & $95^{\circ} \mathrm{C}$ & $78.90(79.54)$ & $6.38(6.50)$ & $6.82(7.29)$ \\
PMBMNPn (Resin) & $\left(\mathrm{C}_{28} \mathrm{H}_{26} \mathrm{~N}_{2} \mathrm{O}_{2}\right)_{\mathrm{n}}$ & $115^{\circ} \mathrm{C}$ & $79.40(77.45)$ & $6.42(6.32)$ & $6.61(6.54)$ \\
\hline
\end{tabular}

The results of FTIR (Fourier Transform Infra-Red) Spectra of Schiff bases and resins are shown in Figure- 3 and Figure-4. The spectra of each are sectioned into three main regions: (1) $4000 \mathrm{~cm}^{-1}$ to $2000 \mathrm{~cm}^{-1}$, (2) $2000 \mathrm{~cm}^{-1}$ to $1000 \mathrm{~cm}^{-1}$, and (3) 1000 to $600 \mathrm{~cm}^{-1}$ respectively.

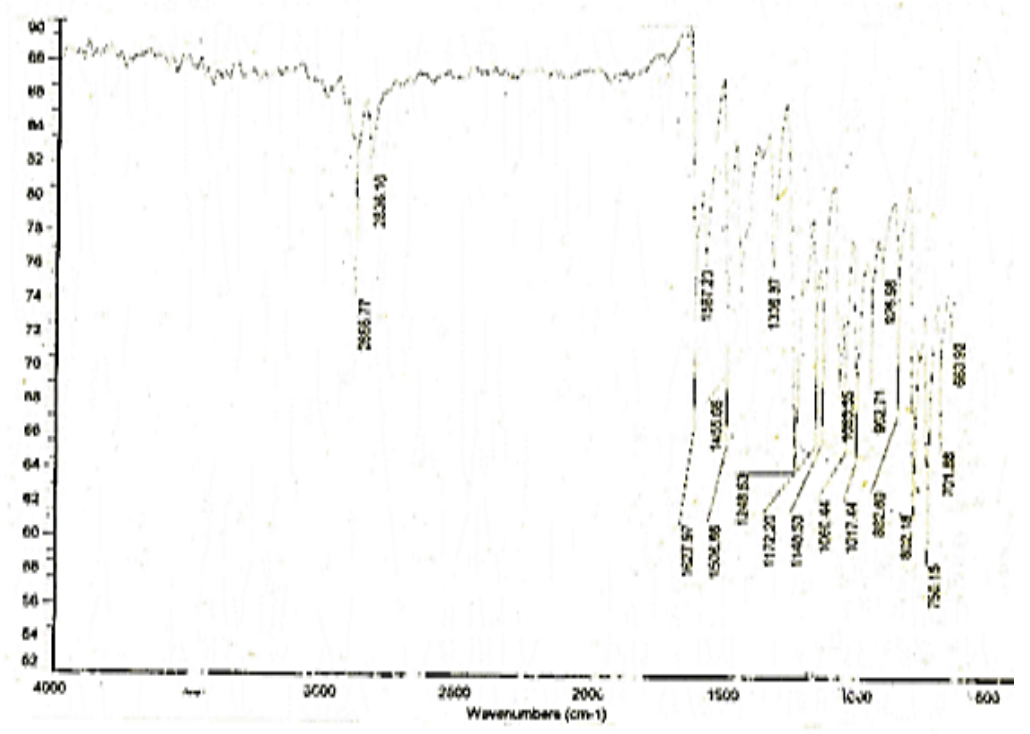

Fig.-3: FTIR Spectra of Schiff base (BMNPn)

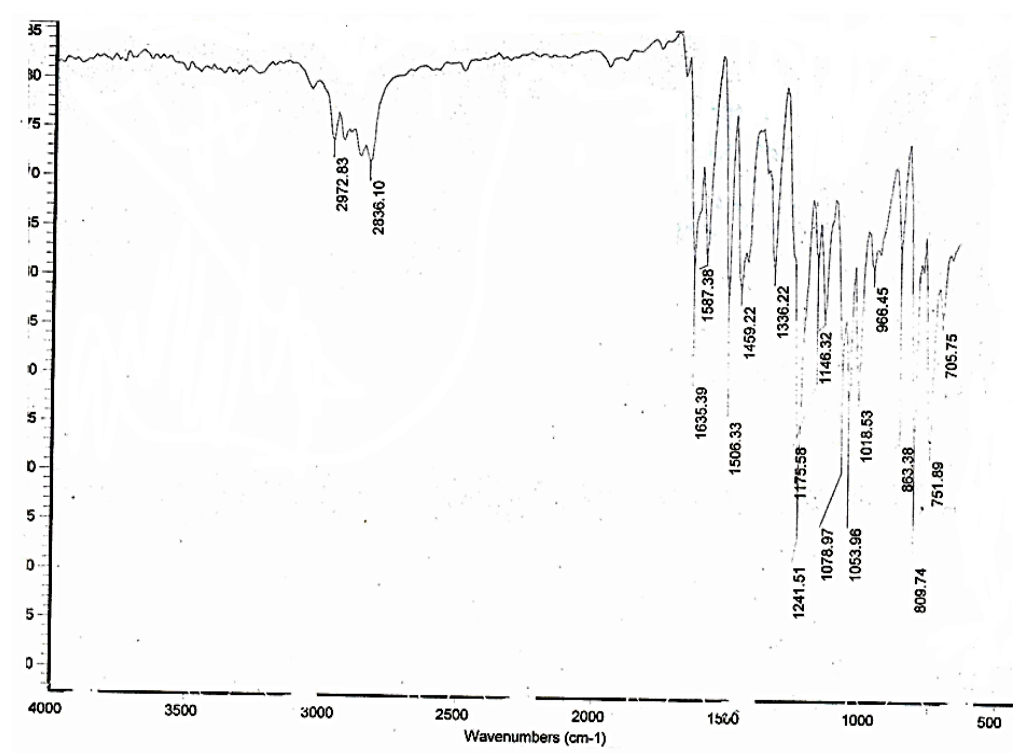

Fig.-4: FTIR Spectra of Resin (PMBMNPn) 
Preparation, Characterization, Viscosity and Thermal Analysis of a Schiff-Based Resin derived from 2-Methoxy-1-Napthaldehyde

Table-2: Results of Spectrophotometric Studies in DMF as Solvent

\begin{tabular}{ll|c|c|c|c}
\hline BMNPn & (Schiff base) & $\lambda_{\max }(\mathbf{n m})$ & 270 & 300 & 348 \\
\hline PMBMNPn & (Resin) & $\lambda(\mathbf{n m}),\left(\mathbf{1 \%} \mathbf{\varepsilon}, \mathbf{L} \cdot \mathbf{g}^{-1} \mathbf{c m}^{-1}\right)$ & $280(253.5)$ & $330(401.3)$ & $382(365.4)$ \\
\hline
\end{tabular}

The Schiff base displayed various vibrations of fluctuating intensities above $3000 \mathrm{~cm}^{-1}$ due to aromatic ${ }^{v} \mathrm{C}-H$ stretching, and the bands around $2820 \mathrm{~cm}^{-1}$ and $3000 \mathrm{~cm}^{-1}$, due to aliphatic ${ }^{v} \mathrm{C}-H$ frequencies. The compound PMBMNPn at $2972 \mathrm{~cm}^{-1}$ and $2836 \mathrm{~cm}^{-1}$ show stretching vibrations due to aliphatic ${ }^{v} \mathrm{C}-H$ group. The resins PMBMNPn showed more stronger absorptions at $1635 \mathrm{~cm}^{-1}$ of ${ }^{v} \mathrm{C}=N$ stretching, in comparison with BMNPn that was offering comparatively medium bands thus, approving the compound's structure. The resin PMBMNPn showed a shift of $8 \mathrm{~cm}^{-1}$ towards higher frequency in comparison with the Schiff base, and is due to polymerization.

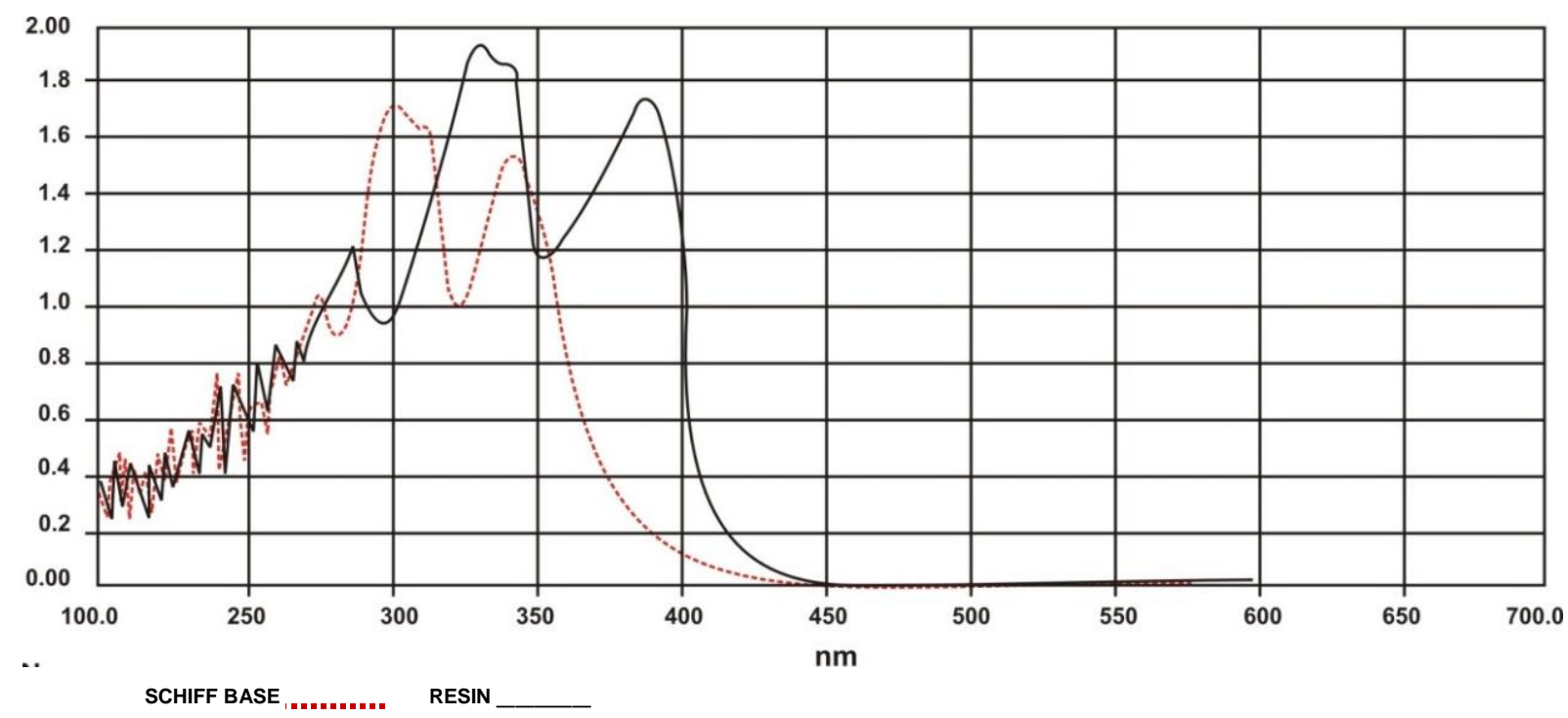

Fig.-5: The UV/Visible Absorption Spectrums of Schiff base (BMNPn) and Resin (PMBMNPn)

The UV/Visible absorption spectrums of Schiff base (BMNPn) and Resin (PMBMNPn) are shown in Figure-5. The spectrums of BMNPn showed 3 bands at 270nm, 300nm, and at 348nm with molar absorptivities 20739.0 L.mol${ }^{-1} \mathrm{~cm}^{-1}, 34907.6 \mathrm{~L} \cdot \mathrm{mol}^{-1} \mathrm{~cm}^{-1}, 31211.5 \mathrm{~L} \cdot \mathrm{mol}^{-1} \mathrm{~cm}^{-1}$, due to $\pi-\pi *$ evolutions in aromatic napthyl ring system and due to $\pi-\pi^{*}$ changes concerning napthyl rings and ${ }^{v} C=N \pi$-electrons. The resin PMBMNPn, displayed absorptions at $280 \mathrm{~nm}, 330 \mathrm{~nm}$ and at $382 \mathrm{~nm}$ with $\left(\varepsilon 1 \%=253.5 \mathrm{~L} \cdot \mathrm{g}^{-1} \mathrm{~cm}^{-1}, 401.3 \mathrm{~L} \cdot \mathrm{g}^{-1} \mathrm{~cm}^{-1}\right.$, and $365.4 \mathrm{~L} \cdot \mathrm{g}^{-1} \mathrm{~cm}^{-1}$ ) due to $\pi-\pi^{*}$ shifts in napthyl rings and $\pi-\pi^{*}$ shifts relating napthyl rings and conjugated $C=N, \pi$-electron systems. A shift towards longer wavelengths of 10 to $34 \mathrm{~nm}$ was perceived in the first three bands of resin PMBMNPn in comparison with Schiff base due to poly condensation as shown in Table-2 above. The thermo analytical plots were obtained by using Pyris Diamond TGA (Thermo Gravimetric Analyzer) from $24^{\circ} \mathrm{C}$ to $600^{\circ} \mathrm{C}$ with a nitrogen flow rate of $5 \mathrm{~mL} / \mathrm{min}$ at a heating rate of $25 \mathrm{~mL} / \mathrm{min}$ in an inert atmosphere [1].

Thermal analyses of the Schiff base BMNPn is shown in Figure-6, and Resin PMBMNPn is shown in Figure-7. The weight loss of about $0.8 \%$ in the region of $50-100^{\circ} \mathrm{C}$ as shown in Figure- 6 is due to removal of water from the sample. Within 200 and $265^{\circ} \mathrm{C}$, the material faced quick weight loss, with the rate of loss $2.18 \%$ per ${ }^{\circ} \mathrm{C}$ at $250^{\circ} \mathrm{C} T_{\max }$ (maximum rate of weight loss). The total or $100 \%$ weight loss is also observed at $270^{\circ} \mathrm{C}$.

Two endotherms were detected in the DTA plot at $88^{\circ} \mathrm{C}$ and $265^{\circ} \mathrm{C}$. The first agrees to the melting of the Schiff base and second with DTA peak is linked to the vaporization/volatilization whereas the resin PMBMNPn displayed first weight loss of about $2 \%$ within 50 to $100^{\circ} \mathrm{C}$ due to removal of $\mathrm{H}_{2} \mathrm{O}$ from compound. Within 280 and $350^{\circ} \mathrm{C}$, the compound faced fast weight loss with the degree of loss $1.97 \% /{ }^{\circ} \mathrm{C}$ at $322^{\circ} \mathrm{C}$ i.e. the maximum rate of weight loss, $T_{\max }$. The $100 \%$ weight loss observed at $500^{\circ} \mathrm{C}$. 


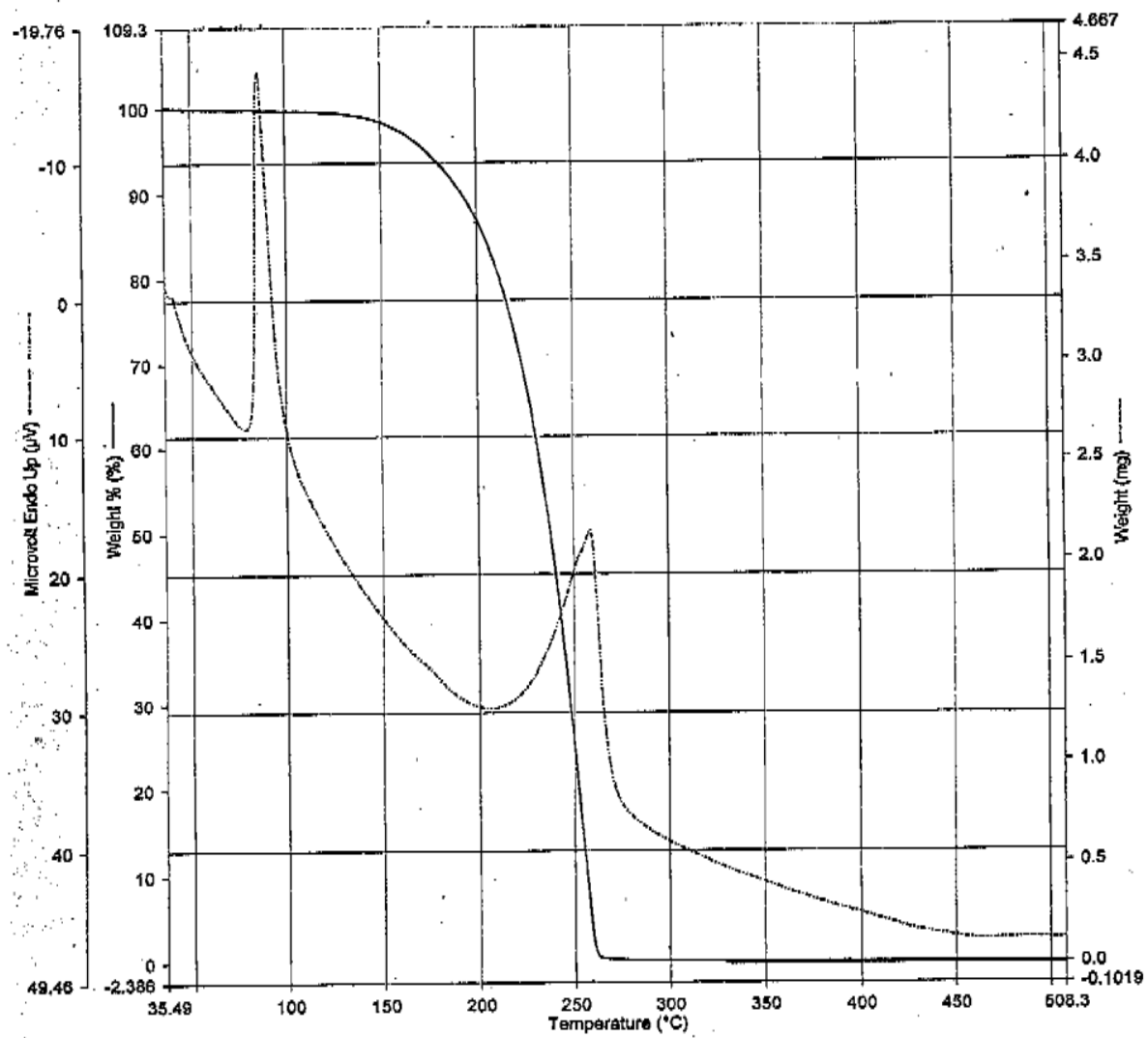

Fig.-6: Thermal Analyses of the Schiff base BMNPn

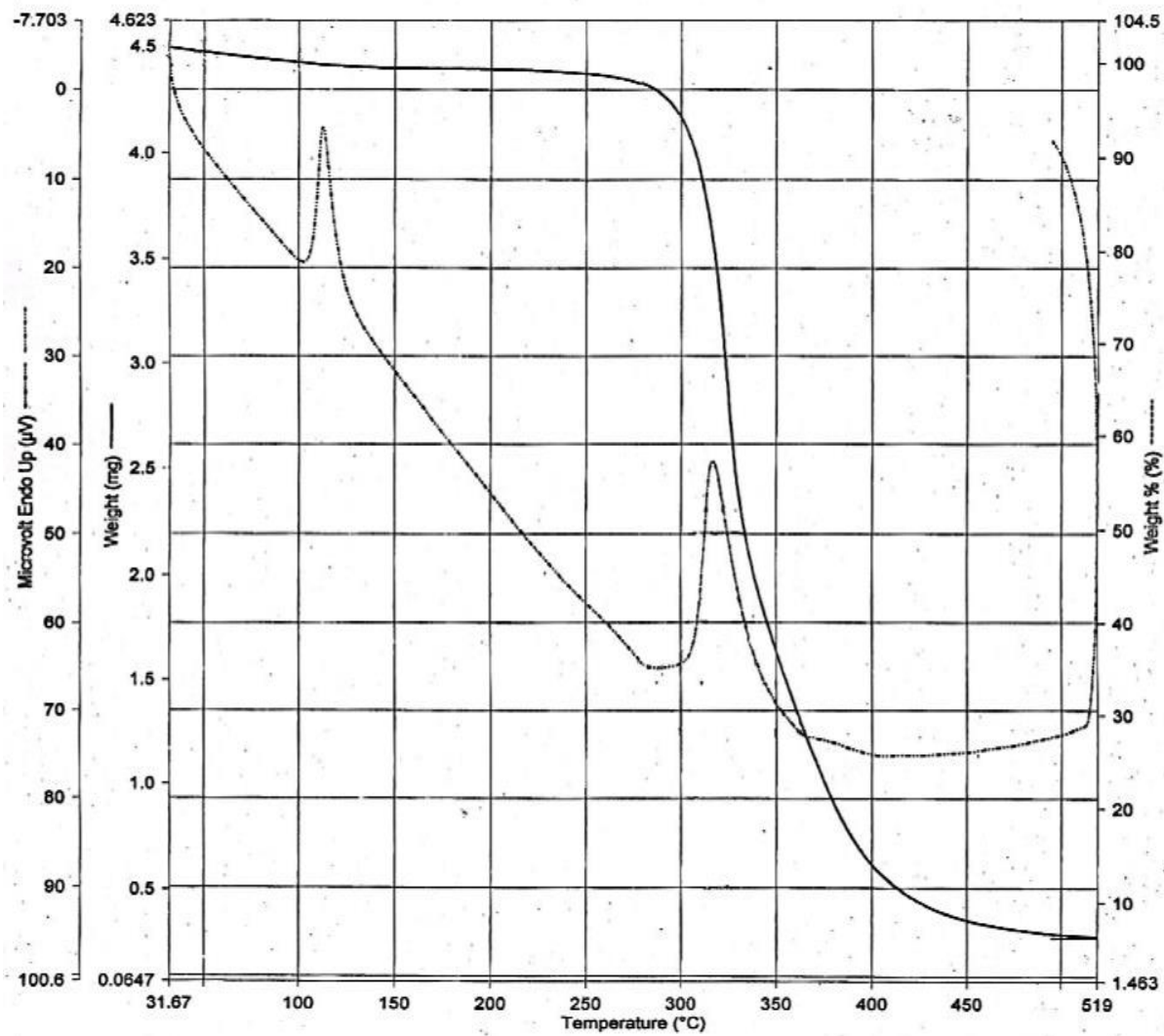

Fig.-7: Thermal Analyses of the Resin PMBMNPn 
Preparation, Characterization, Viscosity and Thermal Analysis of a Schiff-Based Resin derived from 2-Methoxy-1-Napthaldehyde

Reduced viscosity vs concentration of BMNPn at different temperatures

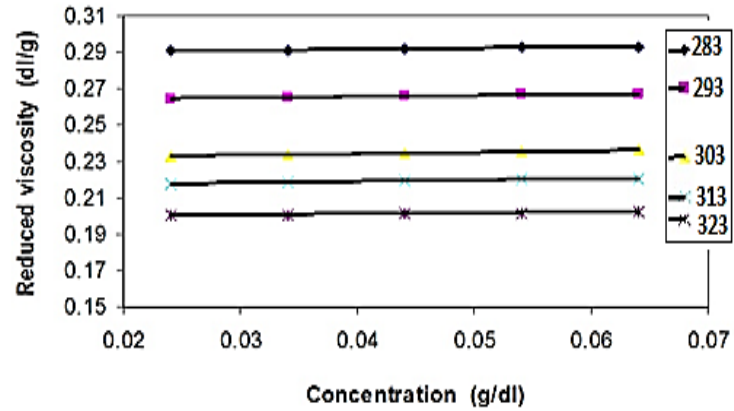

(a)
Reduced viscosity vs concentration of PMBMNPn at different temperatures

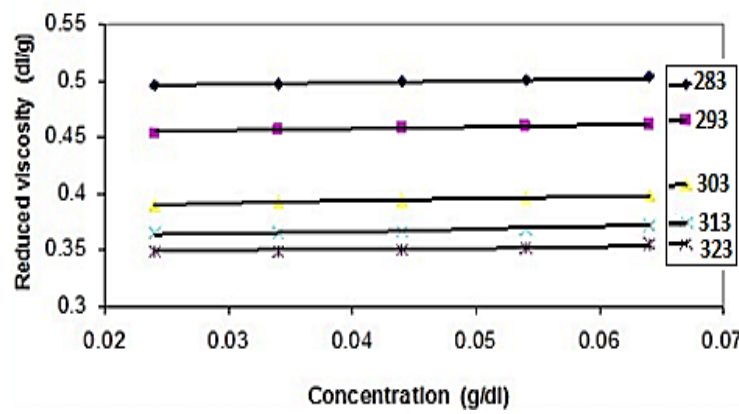

(b) Resin

Fig.-8: Reduced viscosity vs Concentration at different temperature of (a) Schiff base, (b) Resin

Two further strong endotherms were detected in the DTA curve at $115^{\circ} \mathrm{C}$ and $317^{\circ} \mathrm{C}$. The first one agrees to the melting of the resin and the other one was related to the vaporization/volatilization/decomposition. The viscometric measurements of all compounds were calculated by using the calibrated Ostwald's Viscometer. The compounds of concentrations 0.024 to $0.064 \mathrm{~g} / \mathrm{dL}$ were equipped by adding Dimethyl formamide to the re-weighed Schiff base or resin sample in a volumetric flask. The viscometer was occupied with $15 \mathrm{~mL}$ of solution with concentrations 0.024 to $0.064 \mathrm{~g} / \mathrm{dL}$ and a flow time at $283^{\circ} \mathrm{K}$ to $323^{\circ} \mathrm{K}$ with an interval of $10^{\circ} \mathrm{K}$ were measured [7]. From the flow time of the solvent and solution the parameters discussed in the beginning were calculated.

The graph-plot plotted between concentrations and $\eta_{\text {reduced }}$ as shown in Figure-8 (a) \& (b) showed linear relationship obeying Huggin's equation. The reduced viscosity $\eta_{\text {reduced }}$ of Schiff base was within $0.2-0.4 \mathrm{dL} / \mathrm{g}$ and for resin $0.3-0.5 \mathrm{dL} / \mathrm{g}$. The resin showed enhancement in reduced viscosity $\eta_{\text {reduced }}$ as compared to its Schiff base and the results indicated that values of reduced viscosity rises with the escalation in concentration. Intrinsic viscosity is directly related to the polymer sizes and as the polymeric chain increases the molecule becomes huge, resulting into a rise in intrinsic viscosity. Table-3 shows the values of intrinsic viscosity $\eta$. For Schiff base it was $0.2890-0.2015 \mathrm{dL} / \mathrm{g}$ and for resin $0.490-0.345 \mathrm{dL} / \mathrm{g}$ exhibiting that the values increases as the molecular weight increases.

Table-3: Intrinsic Viscosity values of Schiff base and Resin (dL/g)

\begin{tabular}{l|c|c|c|c|c}
\hline \multirow{2}{*}{ Compounds } & \multicolumn{5}{|c}{ Temperature $^{\circ} \mathbf{K}$} \\
\cline { 2 - 6 } & $\mathbf{2 8 3}$ & $\mathbf{2 9 3}$ & $\mathbf{3 0 3}$ & $\mathbf{3 1 3}$ & $\mathbf{3 2 3}$ \\
\hline BMNPn & 0.2890 & 0.2629 & 0.2310 & 0.2160 & 0.2015 \\
PMBMNPn & 0.4908 & 0.4505 & 0.3860 & 0.3593 & 0.3449 \\
\hline
\end{tabular}

The absolute viscosity $\eta_{a b s}$ calculated for Schiff base BMNPn was 0.199-0.430 and for resin PMBMNPn 0.286-0.464 m.N.s $/ \mathrm{m}^{2}$. The values of $\eta_{a b s}$ for Schiff base and Resin rises with the escalation in concentration due to rise in density of polymeric solution, and reduced with elevated temperature. The $\Delta G_{V}$ values of the prepared compounds rise with temperature and concentration, and were within the range for BMNPn 13.936-14.397 K.J.mol ${ }^{-1}$ and for resin PMBMNPn 14.383-15.279 K.J.mol ${ }^{-1}$. The polymeric resin possess weaker associations and easily astounded during the process of flow, but as the concentration rises the connotations become stronger and gets least affected [8]. The increase in $\Delta G_{V}$ with elevation in temperature indicated conversion of shape of molecules of polymeric resin [15],[17]. The values of entropy were within -0.00447 to $0.00322 \mathrm{~g} / \mathrm{dL}$ and for resin -0.01965 to $0.20258 \mathrm{~g} / \mathrm{dL}$. The negative values indicated order in the system. 
V. CONCLUSION

A new Schiff base and a resin was synthesized, and thoroughly characterized via elemental microanalysis, FTIR, UV/VIS Thermo Analytical (TA) studies and viscometery. The CHN values of the compounds found closely correlated to the calculated values conforming the formation of compounds. The resin indicated more stronger absorption band at $1635 \mathrm{~cm}^{-1}$ of azomethine ${ }^{v} \mathrm{C}=N$ stretching vibration than the Schiff base, approving the structure of the newly prepared resin. A shift of absorption maxima towards longer wavelengths of 10 to $34 \mathrm{~nm}$ was detected in the first three absorption bands of resin PMBMNPn as compared to Schiff base BMNPn. A significant elevation in $\eta$ for resin was observed as compared to Schiff base.

\section{ACKNOWLEDGEMENT}

The authors are thankful to Dr. M. A. Kazi Institute of Chemistry, University of Sindh, Jamshoro, Pakistan for providing research facilities at Analytical Chemistry Labs. The CHN analysis was conducted at Elemental Microanalysis Ltd. Carlo Elba Devon, United Kingdom, H.E.J. Research Institute of Chemistry, University of Karachi, Pakistan and NCEAC, University of Sindh, Jamshoro. The authors are also thankful to Incharge, Softronix Science Simulation Lab (FF-21, UBIT Building), Department of Computer Science, University of Karachi, Pakistan for providing support for performing data analysis, software based simulation, and document processing of this Research paper.

\section{REFERENCES}

[1] AK Shah, ZM Ali, AR Memon, AJ Laghari, MA Mughal, SFA Shah, Hussain Saleem, "Exploitation of Low Cost Coal Fly Ash Adsorbent with Coagulants for the Treatment of Industrial Complex Nature Dyes Wastewater", International Journal of Scientific \& Engineering Research, Volume 4, Issue 9, (September-2013).

[2] Bhavna Shah, Ajay Shah, Nayan Patel, Pathik Shah, "Synthesis, Characterization and Analytical Applications of Chelating Resin containing Orcinol”, Polish Journal of Chemical Technology, 14, Issue 2, pp.88-96, (2012).

[3] E Ispir, S Serin, "New Immobilized Schiff bases", Journal of Thermal Analysis, Vol 94; 1, 281 (2008).

[4] El-Sayed M.E. Mansour, A. A. Kaseem, H. Nourel-Din, A. A. El-Toukhy, "Synthesis and Properties of some Schiff base Polymers containing Sulfur", Macromolecular Reports, 28, 103, (1991).

[5] MA Mughal, AH Mughal, ZM Ali, GZ Memon, MY Khuhawar, Hussain Saleem, "New Antimicrobial Schiff base Polymers derived from 6, 6-Methylenebis (1-Napthaldehyde)", International Journal of Scientific \& Engineering Research, Volume 4, Issue 9, (September-2013).

[6] MA Mughal, AH Mughal, ZM Ali, GZ Memon, MY Khuhawar, Hussain Saleem, "Synthesis, Characterization and Antibacterial and Antifungal Studies of Schiff base Polymers derived from Methylene bis Cinnamaldehyde", IOSR Journal of Engineering (IOSRJEN), Vol. 3, Issue 10, pp.48-55, (October 2013).

[7] MA Mughal, AH Mughal, ZM Ali, Hussain Saleem, "Antimicrobial Viscometric Studies of Thermally Stable Metal based Schiff Base Polymer derived from 4, 4-Methylene bis Furfuraldehyde", International Journal of Advancements in Research \& Technology, Volume 2, Issue 8, (August-2013).

[8] MG Kim, "Examination of Selected Synthesis Parameters for Wood Adhesive-Type Urea-Formaldehyde Resins by 13C NMR Spectroscopy", III; Journal of Applied Polymer Science, 80(14) 2800, (2001).

[9] MY Khuhawar, A Shah, MA Mughal, "Preparation and Characterization of some Schiff base Polymers derived from 4,4-methylene bis (Cinnamaldehyde)", Chinese Journal of Polymer Science (2007).

[10] ON Kuznetsova, AK Sakhapova, VP Arkhireev, RR Kadyrov, "Applications of Acetone-Formaldehyde Resins for Hydraulic Seal of Oil Wells", Polymer Science Series D, 1, 4, 249-252, Springer, (2008)

[11] R Mercier, T Pascal, B Sillion, “Thermosetting Polyimide Schiff base Resins, their Preparations, Applications”, US Patent 5,064,934, Google Patents, (1991).

[12] S Samal, NK Mohapatra, S Acharya, "Chelating Resins VII: Studies of Chelating Resins of Formaldehyde and Furfuraldehyde Condensed Phenolic Schiff base derived from 4,4-diaminodiphenyl Sulphone”, Reactive and Functional Polymers, 42; 37-52, Elsevier Science, (1999).

[13] S Samal, RR Das, D Sahoo, "Chelating Resins. III. Synthesis, Characterization and Capacity Studies of Formaldehyde Condensed Phenolic Schiff bases derived from 1,2-diamines and Hydroxyl”, In Journal of Applied Polymer Science, Vol.62, 1437-1444, Dept. of Chemistry, India. (1996).

[14] S Samal, RR Das, S Acharya, "A Comparative Study on Metal ion uptake behavior of Chelating Resins derived from the Formaldehyde-Condensed Phenolic Schiff bases of 4,4'-diaminodiphenyl Sulfone and Hydroxy benzaldehydes", Dept. of Material Sciences, South Korea, Polym, Plast. Technol. Eng., 41(2), 229-246, (2002).

[15] SM Laghari, MH Isa, AB Abdullah, AJ Laghari, Hussain Saleem, Microwave Individual and Combined Pre-Treatments on Lignocellulosic Biomasses", IOSR Journal of Engineering (IOSRJEN), Vol. 4, Issue 2, Ver. 6 (February 2014), pp.14-28.

[16] YSR Quanyin, W Weizhong, M Xinwei, "Catalytic Cure of Urea Formaldehyde Resins with Different Structures", Thermochimica Acta, 253; 307-316, Elsevier Science. (1995).

[17] ZM Ali, MA Mughal, AJ Laghari, AK Ansari, Hussain Saleem, "Polymeric Cellulose Derivative: Carboxymethyl-Cellulose as useful Organic Flocculant against Industrial Waste Waters", International Journal of Advancements in Research \& Technology, Volume 2, Issue 8, (August-2013) 


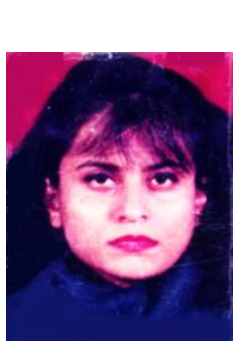

\section{AUTHORS}

Moina Akhtar Mughal is presently working as Assistant Professor at Dr. M. A. Kazi Institute of Chemistry, University of Sindh, Jamshoro, Pakistan. She has obtained her M.Sc. in Organic Chemistry in 1995, and M.Phil. in 2003 from University of Sindh, Jamshoro, Pakistan. She has been awarded $\mathrm{Ph} . \mathrm{D}$. from same university in 2014. She has teaching experience of more than 17 years. She is the author of several research articles of national and international repute.

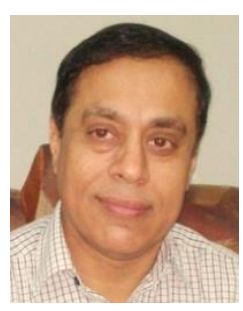

Akhtar Hussain Mughal is Professor and Director at the Institute of Physics, University of Sindh, Jamshoro, Pakistan. He was awarded Ph.D. in Experimental High Energy Physics in 1991 from Brunel University, London, UK, in the field of U.V. Photocathodes for Solid Scintillator Proportional Counter. He has completed number of research projects in the field of Gamma Radiation Detectors Prototype Photosensitive Multiwire Proportional Counter. His areas of research are novel UV-sensitive, air-stable solid photocathodes for use in solid Scintillator, Proportional counters, new Photocathodes for fast gaseous detectors, reflective UV Photocathodes for Position Sensitive Gaseous Detectors, Investigation of new Low Ionization Potential Compounds as UV-Photocathodes in vacuum and gas media.

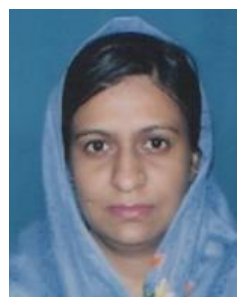

Zeenat Muhammed Ali is presently working as Assistant Professor in Chemical Engineering Department, Mehran University of Engineering \& Technology (MUET), Jamshoro, Sindh, Pakistan. She has been recently awarded Ph.D. in 2014. She has also obtained B.E. in Chemical Engineering in 1997 and M.E. in Environment Engineering in 2002 from MUET, Jamshoro. She has extensively worked in the area of Flocculation under Ph.D. studies and extracted natural flocculants from their indigenous sources and applied for water treatment for removal of turbidity, total dissolved solids and heavy metals. She has presented her work in various national and international conferences. Her work is published in various journals of repute.

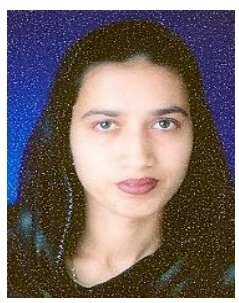

Ghulam Zuhra Memon is an Assistant Professor at Dr. M. A. Kazi Institute of Chemistry, University of Sindh, Jamshoro, Pakistan. She got Ph.D. in Analytical Chemistry from NCEAC, and M.Sc. in Physical Chemistry from University of Sindh, Jamshoro, Pakistan. She has worked as Research Associate for three years from April 2005 till Feb 2008. Thereafter she has served as Lecturer from Feb 2008 till April 2010 and Assistant Professor since April 2010 till date at Dr. M. A. Kazi Institute of Chemistry, University of Sindh, Jamshoro, Pakistan. She has over all teaching and research experience of eight years. She is an active researcher. Her research interest is in removal of toxic chemicals from water using cost effective agricultural waste material. She has also conducted research on assessment of toxic metals in soil and industrial effluents and molecularly imprinted polymers.

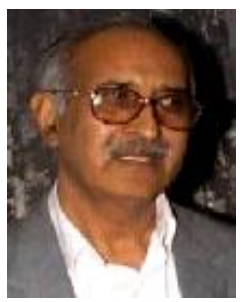

Muhammad Yar Khuhawar is Professor Emeritus, leading researcher and a versatile educator with distinguished academic carrier producing 25 Ph.D., 9 M.Phil. and 3 M.E. research scholars. He is honored with large number of National Awards, including Izaz-e-Kamal and Sitar-e-Imtiaz by President of Islamic Republic of Pakistan for achievements in scientific research. He is well known scholar having 35 years experience of teaching and research at higher education. Administrated number of fully funded research schemes and various academic tasks. National reputation for launching highly productive research workspace, in spite of meager research facilities available. He is actively committed to the field of research yielding over 283 publications in national and international journals. A large number of them are in the field of chromatography and electrophoresis for the analytical methods development for metals, non-metals and biological active compounds from wide variety of real samples; the synthesis of a number of schiff base polymers; new stationary phases for gas chromatography and sensitive liquid chromatography procedures for the determination of pesticide malathion.

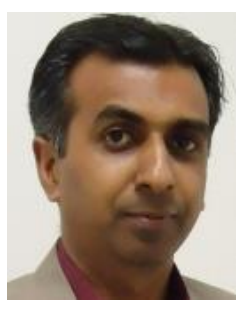

Hussain Saleem is Assistant Professor and Ph.D. Research Scholar at Department of Computer Science, University of Karachi, Pakistan. He received B.S. in Electronics Engineering from Sir Syed University of Engineering \& Technology, Karachi in 1997 and has done Masters in Computer Science from University of Karachi in 2001. He also received Diploma in Statistics from University of Karachi in 2007. He bears vast experience of more than 17 years of University Teaching, Administration and Research in various dimensions of Computer Science. Hussain is the Senior Instructor and has been associated with the Science Labs at Aga Khan Ex. Students Association Karachi since 1992. He served as Bio-Medical Engineer at Aga Khan University in 1999-2000, where he practiced to learn and handle various chemical lab tools e.g. Bio-Chemistry, Histology, Histopathology, Sample Chemistry Analyzers, Radiology and MRI equipments. Hussain is the Author of more than 33 International Journal publications and co-author of about 10 Monographs and he is Reviewer of various International Journals globally. His field of interest is Software Science, System Automation, Hardware Design \& Engineering, Data Analysis, and Simulation \& Modeling. Hussain is a good speaker and has been invited as guest in TV programs and disseminated knowledge over latest technology trends. He is senior member of PEC (Pakistan Engineering Council), IEEE, ACM, IACSIT, and SDIWC. 